\title{
Surveillance of healthcare-associated infections in a neonatal intensive care unit in Italy during 2006-2010
}

Valeria Crivaro ${ }^{1,2}$, Lidija Bogdanović ${ }^{1}$, Maria Bagattini ${ }^{1}$, Vita Dora lula ${ }^{3}$, Mariarosaria Catania ${ }^{3}$, Francesco Raimondi ${ }^{4}$, Maria Triassi ${ }^{1}$ and Raffaele Zarrilli, ${ }^{1,5^{*}}$

\begin{abstract}
Background: Healthcare-associated infections (HAls) are a frequent complication associated with hospitalization of infants in neonatal intensive care units (NICUs). The aim of this study was to evaluate and describe the results of surveillance of HAls in a III level NICU in Naples, Italy during 2006-2010.

Methods: The surveillance covered 1,699 neonates of all birth weight (BW) classes with > 2 days NICU stay. Infections were defined using standard Centers for Disease Control and Prevention definitions adapted to neonatal pathology and were considered to be healthcare-associated if they developed $>2$ days after NICU admission.

Results: One hundred-fifty-three HAls were diagnosed with a frequency of $9 \%$ and an incidence density of 3.5 per 1000 days of hospital stay. HAls developed in all BW classes, but patients weighing $\leq 1000 \mathrm{~g}$ at birth were more affected with a decreasing trend from the lowest to the highest BW classes. Sepsis proved to be the most frequent infection (44.4\%), followed by urinary tract infection (UTI) (28.8\%), pneumonia (25.5\%) and meningitis (1.3\%). Device associated infections (i.e. central line-associated bloodstream infections (BSIs), umbilical catheter-associated BSI and ventilator associated pneumonias (VAPs) represented $64.1 \%$ of all HAls. Most frequent pathogens responsible for all types of infections were: P. aeruginosa (17\%), C. parapsilosis (16.3\%), E. coli (13.1\%), C. albicans (10.5\%), non- extended spectrum beta-lactamase (ESBL) K. pneumoniae (7.8\%), and coagulase-negative Staphylococci (5.2\%). No microbiological diagnosis was achieved for $6.5 \%$ of infections.
\end{abstract}

Conclusions: HAls developed in all BW classes but low BW neonates were at major risk to acquire HAls in our NICU. Use of central line-, umbilical-catheter and mechanical ventilation was associated with higher risk of infection. Our findings highlight the importance of an extensive surveillance approach in the NICU setting, which includes all BW classes of neonates and monitors infections associated with the use of medical devices.

Keywords: Neonatal intensive care units, Healthcare-associated infections, Active surveillance

\section{Background}

Healthcare-associated infections (HAIs) are frequent and critical complications associated with hospitalization of neonates, especially very low birth weight (VLBW) neonates, in neonatal intensive care units (NICUs) [1,2]. Active surveillance systems for HAIs in NICUs have been developed in USA and Canada by the National Healthcare

\footnotetext{
*Correspondence: rafzarri@unina.it

'Department of Public Health, University of Naples "Federico II", Naples, Italy ${ }^{5}$ Italian Study Group of Hospital Hygiene, Italian Society of Hygiene, Preventive Medicine and Public Health, (GISIO), Rome, Italy

Full list of author information is available at the end of the article
}

Safety Network (NHSN) [3,4], the Vermont Oxford Network [5,6] and the Canadian Neonatal Network [7]. In Europe, surveillance systems for HAIs in NICUs are active in Germany [8,9] and in England [10].

The first national report on HAIs in Italian intensive care units (ICUs) has recently been published [11]. The document shows the results of HAIs surveillance activities for the 2009-2010 period and mainly focuses on adult ICUs, with a very limited contribution of pediatric ICUs and none of NICUs.

While several studies have shown the spread of specific nosocomial pathogens, such as ESBL producing 
Enterobacteriaceae [12,13], Pseudomonas aeruginosa [14], methicillin resistant Staphylococcus aureus [15], extensively drug resistant (XDR) Acinetobacter baumannii [16], Candida parapsilosis [17] in Italian NICUs, few studies were performed on the prevalence [18] or incidence of HAIs in NICUs [19-21]. Active surveillance of HAIs was utilized in the majority of the studies from Italian NICUs [12-16,18,21].

Objective of the present study was to describe and discuss the results of surveillance of HAIs in a neonatal intensive care unit in Italy during 2006-2010 using the NHSN surveillance protocol.

\section{Methods}

\section{Setting}

The University of Naples "Federico II" NICU is a III level NICU with a total of 25 incubators and cradles. The ward serves the University Obstetric Clinic (approximately 2000 births/year) which is both a high risk pregnancy center and an obstetric emergency service. Moreover, the NICU admits outborn neonates from the regional Newborn Emergency Transport Service.

\section{Active surveillance}

Healthcare-associated infections (HAIs) active, patientbased surveillance (AS) is continuously carried out by trained personnel. Data are collected on weekly basis directly from patient's charts. Any clinical issues are directly discussed with caregivers. Data are analyzed on monthly basis and expressed as monthly report. Monthly report consist of patient data, data on swab isolations of sentinel pathogens, device utilization ratios and infection data. All neonates with $>2$ days NICU stay enter the AS system and data regarding birth (birth weight (BW), gestational age, type of delivery, and Apgar score), invasive device exposure (days of umbilical and central line catheterization and of invasive ventilation), antimicrobial therapy exposure (yes/no) and infections are collected. End of surveillance coincides with neonates' discharge from the ward. Infections are defined using standard Centers for Disease Control and Prevention definitions adapted to neonatal pathology [22-24] and are considered to be healthcareassociated if they develop $>2$ days after NICU admission. We exclude neonates with a vertical infection (ie, an infection transmitted from mother to child) or infection acquired during delivery. This paper analyzes data from the HAIs AS system over a 5 years long period (2006-2010). For this study purposes, only sepsis, meningitis, pneumonia, and urinary tract infections (UTIs) were considered. Central line-associated blood-stream infections (BSI), umbilical catheter-associated BSI and ventilator-associated pneumonia (VAP) were attributed if a central line, an umbilical catheter and invasive ventilation, respectively, were in place at the time of or within 48 hours before infection onset [24]. Frequency measures were calculated as percent of infection and as incidence densities, i.e. infection rates per 1000 days of hospital stay or 1000 days of directly related invasive device within $5 \mathrm{BW}$ classes $(\leq 750 \mathrm{~g}$, 751-1000 g, 1001-1500 g, 1501-2500 g, and $\geq 2501$ g). Device utilization rates within such classes were also calculated. The etiology of all infections within each birthweight class was assessed during the study period.

HAIs surveillance is regulated by the Regional Health Authority and it is one of the basic components of the Regional Plan for Healthcare-associated infections Prevention and Control [25]. The HAIs AS system manages data in a cumulative form with the ultimate goal of diseases' surveillance in the population and continuous improvement of quality in healthcare. Results of surveillance activities are periodically reported to the Regional Health Authority. As such, no patient informed consent, nor local Ethical Committee authorization is required.

\section{Statistical analysis}

Data were analysed using SPSS 11.0 (Chicago, IL, USA). Finally, ANOVA or Kruskal Wallis test were used as appropriate to assess significant differences $(\mathrm{p}<0.05)$ in the above-mentioned variables over the five-years study period. Linear regression analysis was performed to detect significant time-dependent and BW-related trends as previously described [26,27].

\section{Results}

Between years 2006 and 20101699 neonates, corresponding to $91.49 \%$ of all admissions to the ward, entered the HAIs AS system and a total of 43447 patient days were registered. The remaining $8.51 \%$ of admissions was excluded because either ineligible (length of stay $<2$ days) or missed by the HAIs AS system. During the study period neonates with $>1000 \mathrm{~g} \mathrm{BW}$ accounted for $74 \%$ of total patient days (1001-1500 g, 1501-2500 g, and $\geq 2501$ g classes representing $26.7 \%, 28.1 \%$, and $19.2 \%$, respectively) while the remaining $26 \%$ was distributed among extremely low BW (ELBW) infants ( $\leq 750 \mathrm{~g}$ and $751-1000 \mathrm{~g} \mathrm{BW}$ classes accounting for $9.1 \%$ and $16.9 \%$ of total patient days, respectively). Statistically significant differences in length of hospitalization over the five-years period were detected in the lower BW classes $(\mathrm{p}=0.003,0.047$, and 0.004 for $\leq 750 \mathrm{~g}, 751-1000 \mathrm{~g}$, and $1001-1500 \mathrm{~g}$ classes, respectively), and total patient days in the $\leq 750 \mathrm{~g} \mathrm{BW}$ class showed a statistically significant decreasing trend over time $\left(\mathrm{R}^{2}=0.228, \mathrm{p}=0.000\right)$ (Table 1$)$.

Percentiles of device utilization rates in the five BW classes are shown in Table 2. No statistically significant differences within each BW class were found over the five years study period for devices utilization rates, except for mechanical ventilation in the 751-1000 g and 10011500 g BW classes ( $p=0.000$ and 0.002 , respectively). The 
Table 1 Neonates data per birthweight category during the study period

\begin{tabular}{|c|c|c|c|c|c|c|}
\hline Year & 2006 & 2007 & 2008 & 2009 & 2010 & Total \\
\hline Hospitalized patients & 339 & 392 & 395 & 427 & 304 & 1857 \\
\hline Surveilled patients & 310 & 357 & 357 & 384 & 291 & 1699 \\
\hline Number of patient days* & 8020 & 9012 & 9259 & 8361 & 8795 & 43447 \\
\hline$\leq 750 \mathrm{~g}$ & 1127 & 890 & 903 & 475 & 564 & 3959 \\
\hline $751-1000 \mathrm{~g}$ & 1939 & 1194 & 1400 & 1055 & 1773 & 7361 \\
\hline $1001-1500 \mathrm{~g}$ & 1628 & 2748 & 2927 & 2258 & 2038 & 11599 \\
\hline $1501-2500 \mathrm{~g}$ & 2084 & 2585 & 2292 & 2731 & 2500 & 12192 \\
\hline$>2500 \mathrm{~g}$ & 1242 & 1595 & 1737 & 1842 & 1920 & 8336 \\
\hline Number of umbilical catheter days* & 729 & 803 & 775 & 924 & 1001 & 4232 \\
\hline$\leq 750 \mathrm{~g}$ & 92 & 94 & 80 & 124 & 112 & 502 \\
\hline 751-1000 g & 180 & 74 & 106 & 88 & 217 & 665 \\
\hline $1001-1500 \mathrm{~g}$ & 191 & 280 & 265 & 259 & 267 & 1262 \\
\hline $1501-2500 \mathrm{~g}$ & 173 & 182 & 166 & 267 & 254 & 1042 \\
\hline$>2500 \mathrm{~g}$ & 93 & 173 & 158 & 186 & 151 & 761 \\
\hline Number of central line days* & 1044 & 1049 & 1374 & 1133 & 1395 & 5995 \\
\hline$\leq 750 \mathrm{~g}$ & 213 & 194 & 214 & 125 & 145 & 891 \\
\hline 751-1000 g & 430 & 213 & 268 & 187 & 370 & 1468 \\
\hline $1001-1500 \mathrm{~g}$ & 187 & 263 & 439 & 396 & 402 & 1687 \\
\hline $1501-2500 \mathrm{~g}$ & 158 & 229 & 271 & 287 & 331 & 1276 \\
\hline$>2500 \mathrm{~g}$ & 179 & 150 & 182 & 138 & 147 & 796 \\
\hline Number of ventilator days* & 1044 & 843 & 1075 & 702 & 1544 & 5208 \\
\hline$\leq 750 \mathrm{~g}$ & 298 & 286 & 362 & 149 & 258 & 1353 \\
\hline $751-1000 \mathrm{~g}$ & 492 & 245 & 214 & 77 & 604 & 1632 \\
\hline $1001-1500 \mathrm{~g}$ & 142 & 97 & 257 & 115 & 334 & 945 \\
\hline $1501-2500 \mathrm{~g}$ & 70 & 142 & 156 & 196 & 208 & 772 \\
\hline$>2500 \mathrm{~g}$ & 42 & 73 & 86 & 165 & 140 & 506 \\
\hline
\end{tabular}

*Data refer to surveilled patients.

latter showed an increasing trend over the studied interval $\left(\mathrm{R}^{2}=0.091, \mathrm{p}=0.020\right)$.

The overall number of HAIs registered during the study period by the local AS system was 153 (9\% total infection rate and 3.5 total incidence density per 1000 days of hospital stay). HAIs developed in all BW classes, but patients weighing $\leq 1000 \mathrm{~g}$ at birth were more affected $(45.8 \%$ of all HAIs) and a statistically significant decreasing trend $\left(R^{2}=0.964, p=0.003\right)$ from the lowest to the highest BW classes in terms of incidence density per 1000 days of hospital stay was observed $(7.83,5.298,3.104,2.297$, and 2.279 in $\leq 750 \mathrm{~g}, 751-1000 \mathrm{~g}, 1001-1500 \mathrm{~g}, 1501-2500 \mathrm{~g}$, and $\geq 2501 \mathrm{~g} \mathrm{BW}$ newborns, respectively). On the whole, sepsis proved to be the most frequent infection (44.4\%), followed by UTIs (28.8\%), pneumonia (25.5\%) and meningitis (1.3\%). Device associated infections (i.e. central lineassociated BSI, umbilical catheter-associated BSI and VAPs) represented $64.1 \%$ of all HAIs. Incidence densities of device-associated infections among the five BW classes are shown in Table 3. Incidence densities of the three types of device associated infections showed no statistically significant differences within each BW class over the five years study period, and within the five years of the study period when related to the five BW classes, with the exception of ventilator-associated pneumonia (VAP) in year 2008, which showed a statistically significant, decreasing trend from the lowest to the highest $\mathrm{BW}$ classes $\left(R^{2}=0.130, p=0.005\right)$.

Etiology of device-associated infections among the five BW classes are shown in Table 4. Most frequent pathogens responsible for all types of infections were: P. aeruginosa (17\%), C. parapsilosis (16.3\%), E. coli (13.1\%), C. albicans (10.5\%), non-ESBL K. pneumoniae (7.8\%), and coagulase-negative Staphylococci (5.2\%). The remaining $23.5 \%$ of infections were caused by either Enterobacteriaceae, Candida species, S. aureus or other gram-positive cocci, each accounting for less than $5 \%$ of all infections. No statistically significant differences during the five-years period were detected among such pathogens. Moreover, for $6.5 \%$ of infections no microbiological 
Table 2 Percentiles of the distribution of device utilization rates in surveilled neonates during the study period

\begin{tabular}{llllll}
\hline & $\mathbf{1 0}^{\circ}$ & $\mathbf{2 5}^{\circ}$ & $\mathbf{5 0}^{\circ}$ & $\mathbf{7 5}^{\circ}$ & $\mathbf{9 0}^{\circ}$ \\
\hline Umbilical catheter utilization rate & & & & & \\
\hline$\leq 750 \mathrm{~g}$ & .000 & .021 & .105 & .191 & .447 \\
$751-1000 \mathrm{~g}$ & .000 & .029 & .075 & .125 & .169 \\
$1001-1500 \mathrm{~g}$ & .052 & .058 & .105 & .142 & .178 \\
$1501-2500 \mathrm{~g}$ & .021 & .049 & .080 & .117 & .149 \\
$>2500 \mathrm{~g}$ & .017 & .041 & .081 & .135 & .167 \\
\hline Central catheter utilization rate & & & & & \\
\hline$\leq 750 \mathrm{~g}$ & .000 & .038 & .164 & .395 & .563 \\
$751-1000 \mathrm{~g}$ & .000 & .085 & .159 & .302 & .380 \\
$1001-1500 \mathrm{~g}$ & .017 & .066 & .140 & .200 & .277 \\
$1501-2500 \mathrm{~g}$ & .000 & .030 & .103 & .161 & .213 \\
$>2500 \mathrm{~g}$ & .000 & .037 & .074 & .139 & .221 \\
\hline Mechanical ventilation utilization rate & & & & & \\
\hline$\leq 750 \mathrm{~g}$ & .000 & .117 & .352 & .564 & .748 \\
$751-1000 \mathrm{~g}$ & .000 & .059 & .175 & .329 & .500 \\
$1001-1500 \mathrm{~g}$ & .005 & .015 & .035 & .131 & .190 \\
$1501-2500 \mathrm{~g}$ & .006 & .020 & .051 & .102 & .152 \\
$>2500 \mathrm{~g}$ & .000 & .014 & .039 & .101 & .137 \\
\hline
\end{tabular}

diagnoses were achieved; such cases showed statistically significant differences during the five-years period $(\mathrm{p}=0.024)$ and a statistically significant decreasing trend over the studied interval $\left(\mathrm{R}^{2}=0.116, \mathrm{p}=0.008\right)$.

The most frequent device-unrelated HAIs were UTIs (77.2\% of all), which mainly affected neonates belonging to the 1001-1500 $\mathrm{g}$ and 1501-2500 g BW classes (distribution of UTIs was $0 \%, 9,1 \%, 45.5 \%, 31.8 \%$ and $13,6 \%$ in $\leq 750 \mathrm{~g}, 751-1000 \mathrm{~g}, 1001-1500 \mathrm{~g}, 1501-2500 \mathrm{~g}$, and $\geq 2501$ g BW newborns, respectively). UTIs incidence density per 1000 days of hospital stay showed no statistically significant differences within each BW class over the five years study period, and within the five years of the study period when related to the five BW classes, with the exception of year 2008, which showed a statistically significant increasing trend from the lowest to the highest BW classes $\left(\mathrm{R}^{2}=0.812, \mathrm{p}=0.037\right)$.

Twenty-five percent of UTIs were caused by $E$. coli, followed by $K$. pneumoniae (18.2\%, half of which displayed ESBL phenotype), Candida spp. (15.9\%), P. aeruginosa
(13,6\%), Enterobacter spp. and Enterococcus spp. (6.8\% each); the remaining $13.7 \%$ included ESBL-producing Klebsiella oxytoca and Serratia marcescens, Proteus mirabilis, polimicrobial and undetermined aetiologies.

One half of catheter-unrelated sepsis was not supported by microbiological identification and one half was caused by C. albicans, E. faecalis, P. aeruginosa, and Streptococcus viridans. Pathogens responsible for the 3 ventilator-unassociated pneumonias were S. epidermidis, $E$. coli and $K$. pneumoniae. In one case, meningitis evolved from a $C$. albicans umbilical catheter-associated BSI in $a \leq 750 \mathrm{~g}$ BW neonate, in the other no aetiology was defined (Table 4).

\section{Discussion}

Surveillance is a well-established prevention measure of healthcare-associated infections (HAIs) and reductions in HAIs rates are to be expected on the medium to long term period at those institutions which systematically carry out such activities $[23,28,29]$. HAIs AS in the University of Naples "Federico II" NICU was started in the mid 1990s and has been going on since then according to the Atlanta's CDC methodology (National Nosocomial Infections Surveillance System NNIS before and NHSN nowadays) [22-24]. Data here described show that during the 2006-2010 period no significant change in HAIs rates took place. Nevertheless, when compared to previous data referred to the same NICU over a 54-months period between years 1996 and 2000 [12], our findings demonstrate that HAIs rates, in terms of both total infection rate and total incidence density per 1000 days of hospital stay, were reduced by nearly half in a fourteen years time span ( $9 \%$ and 3.5 vs. $17.2 \%$ and 7.3 ). Further analysis of factors which, other than HAIs AS, led to such variations goes beyond the scope of this research.

Moreover, during the study period here described, two outbreaks $[14,16]$ took place in the ward and this may partially explain the absence of statistically significant changes in all HAIs rates. On the other hand, during one of such outbreaks [14], an intense educational programme on hand hygiene was carried out in the ward and its positive effects may have improved infection rates.

The HAIs AS system here adopted is basically inspired to Centers for Disease Control and Prevention (CDC)'s NHSN - device associated module, thus benchmarking of our data against infection rates of NHSN reports appears

Table 3 Incidence densities of device-associated infections per birth weight category in surveilled neonates

\begin{tabular}{llllll}
\hline Device-associated infection & $\mathbf{5 7 5 0} \mathbf{~ g}$ & $\mathbf{7 5 1 - 1 0 0 0 ~} \mathbf{~}$ & $\mathbf{1 0 0 1 - 1 5 0 0 ~ g}$ & $\mathbf{1 5 0 1 - 2 5 0 0 ~} \mathbf{~}$ & $\mathbf{> 2 5 0 0} \mathbf{~ g}$ \\
\hline Umbilical catheter associated bloodstream infection (pooled mean)* & 6.127 & 0.331 & 1.231 & 0.892 & 1.695 \\
Central catheter associated bloodstream infection (pooled mean)* & 11.636 & 8.644 & 4.731 & 4.544 & 6.981 \\
VAP (pooled mean)* & 9.93 & 6.896 & 1.346 & 1.577 & 5.595 \\
\hline
\end{tabular}

${ }^{*}$ Data refer to cases per 1000 specific device-days. 
Table 4 Etiology of device-associated infections per birth weight category in surveilled neonates

\begin{tabular}{|c|c|c|c|c|c|c|}
\hline Umbilical catheter associated bloodstream infection & $\leq 750 \mathrm{~g}$ & $751-1000 \mathrm{~g}$ & $1001-1500 \mathrm{~g}$ & $1501-2500 \mathrm{~g}$ & $>2500 \mathrm{~g}$ & Total (\%) \\
\hline Candida parapsilosis & 3 & 1 & 2 & 0 & 0 & $6(50)$ \\
\hline Escherichia coli & 0 & 0 & 0 & 2 & 1 & $3(25)$ \\
\hline Candida albicans & 1 & 0 & 0 & 0 & 1 & $2(16.7)$ \\
\hline CONS & 0 & 1 & 0 & 0 & 0 & $1(8.3)$ \\
\hline Total (\% within BW category) & $4(33.3)$ & $2(16.7)$ & $2(16.7)$ & $2(16.7)$ & $2(16.7)$ & $12(100)$ \\
\hline Central catheter associated bloodstream infection & $\leq 750 \mathrm{~g}$ & $751-1000 \mathrm{~g}$ & $1001-1500 \mathrm{~g}$ & $1501-2500 \mathrm{~g}$ & $>2500 \mathrm{~g}$ & Total (\%) \\
\hline Candida parapsilosis & 3 & 4 & 5 & 2 & 3 & $17(35.4)$ \\
\hline Candida albicans & 1 & 3 & 0 & 2 & 1 & $7(14.6)$ \\
\hline Escherichia coli & 0 & 4 & 0 & 0 & 0 & $4(8.3)$ \\
\hline Pseudomonas aeruginosa & 3 & 1 & 0 & 0 & 0 & $4(8.3)$ \\
\hline Klebsiella pneumoniae ESBL+ & 0 & 0 & 1 & 2 & 0 & $3(6.3)$ \\
\hline Serratia marcescens & 2 & 1 & 0 & 0 & 0 & $3(6.3)$ \\
\hline CONS & 0 & 0 & 2 & 0 & 0 & $2(4.2)$ \\
\hline Candida glabrata & 0 & 0 & 1 & 0 & 0 & $1(2.1)$ \\
\hline Enterobacter spp. & 0 & 1 & 0 & 0 & 0 & $1(2.1)$ \\
\hline Enterococcus faecalis & 0 & 0 & 1 & 0 & 0 & $1(2.1)$ \\
\hline Not determined & 0 & 0 & 1 & 0 & 0 & $1(2.1)$ \\
\hline polimicrobial (Candida albicans + Pseudomonas aeruginosa) & 1 & 0 & 0 & 0 & 0 & $1(2.1)$ \\
\hline Rothia mucillaginosa & 0 & 0 & 0 & 0 & 1 & $1(2.1)$ \\
\hline Staphylococcus aureus & 0 & 0 & 0 & 1 & 0 & $1(2.1)$ \\
\hline Streptococcus spp. & 1 & 0 & 0 & 0 & 0 & $1(2.1)$ \\
\hline Total (\% within BW category) & $11(22.9)$ & $14(29.2)$ & $11(22.9)$ & $7(14.6)$ & $5(10.4)$ & $48(100)$ \\
\hline$\underline{\text { VAP }}$ & $\leq 750 \mathrm{~g}$ & $751-1000 \mathrm{~g}$ & $1001-1500 \mathrm{~g}$ & $1501-2500 \mathrm{~g}$ & $>2500 \mathrm{~g}$ & Total (\%) \\
\hline Pseudomonas aeruginosa & 5 & 7 & 0 & 1 & 2 & $15(41.7)$ \\
\hline Acinetobacter baumannii & 2 & 1 & 1 & 0 & 0 & $4(11.1)$ \\
\hline CONS & 0 & 2 & 1 & 0 & 1 & $4(11.1)$ \\
\hline Klebsiella pneumoniae ESBL+ & 1 & 2 & 1 & 0 & 0 & $4(11.1)$ \\
\hline Candida albicans & 1 & 1 & 0 & 0 & 0 & $2(5.6)$ \\
\hline Escherichia coli & 1 & 1 & 0 & 0 & 0 & $2(5.6)$ \\
\hline Not determined & 1 & 0 & 0 & 1 & 0 & $2(5.6)$ \\
\hline Polimicrobial (K. pneumoniae ESBL+ + P. aeruginosa) & 0 & 0 & 0 & 1 & 0 & $1(2.8)$ \\
\hline Staphylococcus aureus & 0 & 1 & 0 & 0 & 0 & $1(2.8)$ \\
\hline Stenotrophomonas maltophilia & 0 & 1 & 0 & 0 & 0 & $1(2.8)$ \\
\hline Total (\% within BW category) & $11(30.6)$ & $16(44.4)$ & $3(8.3)$ & $3(8.3)$ & $3(8.3)$ & $36(100)$ \\
\hline
\end{tabular}

Abbreviations: NICU, neonatal intensive care unit; CONS, coagulase negative staphylococci; ESBL+, extended spectrum beta-lactamase producer; VAP, ventilator-associated pneumonia.

to be methodologically correct. For this purpose, NHSN data reports referred to the 2006-2009 period were considered, while the one referred to year 2010 was excluded because starting from that year bloodstream infections returned to be related to central lines in general, with no distinction between umbilical and central catheters $[3,4,30]$.

Pooled mean infection rates at our institution proved to be higher than those reported by NHSN, yet always lower than the $90^{\circ}$ value for the middle BW classes $(751-1000 \mathrm{~g}$, 1001-1500 g, and 1501-2500 g). On the contrary, extreme BW classes ( $\leq 750 \mathrm{~g}$ and $\geq 2501 \mathrm{~g})$ infection rates constantly performed as high outliers. Such results are not in contrast with the strong, BW-related decreasing trend $\left(R^{2}=0.964, p=0.003\right)$ we observed from the lowest to the highest BW classes, since it refers to the overall infection incidence density per 1000 days of hospital stay and not only to device-associated infections. Moreover, with the 
exception of umbilical catheter utilization rate in $\leq 750 \mathrm{~g}$ BW neonates, our percentile distributions of devices' utilization rates show lower values than those of NHSN. These findings suggest that specific problems may exist in the $\leq 750 \mathrm{~g}$ and $\geq 2501 \mathrm{~g}$ BW classes, but they also point out that comparisons between very diverse healthcare systems may be confounding or not appropriate because of objective differences in clinical practice and standards of care.

A well-established European neonatal surveillance network is Germany's Neonatal-Krankenhaus Infektions Surveillance System (NEO-KISS). Unlike the NHSN surveillance system, the NEO-KISS system monitors HAI occurring in all very low birth weight (VLBW) infants $(\mathrm{BW}<1500 \mathrm{~g})$ in NICUs until discharge, until death, or until they reach $1800 \mathrm{~g}$. The system identifies different BW classes ( $\leq 499$ g, 500-999 g, 1000-1499 g) and makes no distinction between umbilical and central line $[8,9]$. Thus, a possible comparison between our data and the latest NEO-KISS report [31] can only be made for VAP rates in the 1000-1500 BW class, which appear to be similar (1,34 and 1,17 at our NICU and in NEO-KISS, respectively).

A more pertinent benchmarking would be on a national scale. As previously pointed out, though, no data from NICUs is included in the first national report on HAIs in Italian ICUs. A multicentre prospective cohort study in six Italian NICUs lasting 28 months described a $12.8 \%$ infection rate, with an incidence density of 6.93 episodes per 1,000 patient days [21]. A three years surveillance report from a single NICU showed similar results: $13.2 \%$ infection rate with an incidence density of 7.8 episodes per 1,000 patient days [20]. Our data appear to be considerably lower but, again, questions on the accuracy of national-based, yet network-unrelated comparisons arise.

The present study shows that over time a substantial change in HAIs etiology at our NICU has taken place: in the previous decade the most commonly isolated microorganism was Staphylococcus epidermidis, which caused $28 \%$ of all HAIs [12]. During the 2006-2010 period, most frequent pathogens were gram-negative bacteria (P. aeruginosa, E. coli, K. pneumoniae) and fungi (C. parapsilosis, C. albicans), while coagulase-negative Staphylococci dropped down to $5.2 \%$. Such trend proved to be stable over time (no statistically significant differences during the five-years period were detected among such pathogens) and quite well reproducible in all specific types of HAIs (umbilical and central catheter-associated BSIs, VAPs and UTIs). Moreover, it is worth-mentioning that BSIs at our institution were mainly caused by C. albicans and C. parapsilosis. Fluconazole prophylaxis for neonates $\leq 1500 \mathrm{~g}$ BW was introduced during 2009 at our NICU. These findings partially agree with a previous prospective surveillance study on nosocomial infections in six NICUs in Brazil which showed that Gram-negative rods (mainly Klebsiella sp. and E. coli) were responsible for $51.6 \%$ episodes of BSI, Gram-positive organisms and Candida sp. accounted for 37.4 and $11.1 \%$, respectively [32]. On the other hand, our data strongly differ from two recent NICU long period-based reports describing a prevalent gram-positive etiology for BSI [33,34]. These discrepancies may depend on differences in the clinical settings.

Our data also showed that $48 / 60(80 \%)$ BSI were associated with central-line catheter use, 12/60 (20\%) with umbilical catheter. Although data collection is more complicated, we speculate that the separation between umbilical and percutaneous catheters-associated BSIs is worth maintaining in order to better identify problems and prevention strategies.

Interestingly, clinical sepsis (i.e. not determined etiology) significantly decreased during the study period. This should imply less broad spectrum molecules use and targeted antimicrobial prescription, however such variables are not examined in this paper and the considered time interval is probably too short to show variations in bacterial resistance phenotypes.

Most reports on HAIs in NICUs focus on BSIs and, eventually, on VAPs. Our data shows that the most frequent infection after BSIs is UTI. Although UTI were diagnosed according to validated criteria [4], no sterile urine collection through supraumbilical aspiration was performed. In agreement with our data, a previous surveillance study of HAI in an Italian NICU reported that UTI are the third most frequent cause of infection after BSI and pneumonia [20].

Finally, the data reported herein show that HAIs developed in all BW classes. Although a decreasing trend from the lowest to the highest BW classes in terms of incidence density per 1000 days of hospital stay was observed, all device-associated infection rates in $\geq 2501 \mathrm{~g}$ BW neonates proved to be higher than those recorded in the 1000-2500 g BW classes. This is in agreement with other surveillance studies in European NICUs which have also described infectious complications in the upper BW classes [10,20,21,33]. Moreover, this finding underlines the importance of HAIs surveillance in NICUs for all BW classes newborns.

\section{Conclusions}

In our NICU, all BW classes were affected by HAIs, but low birth weight neonates were at major risk to acquire HAIs. Sepsis, UTI and pneumonia were the most frequent infection in our NICU. Because use of central line-, umbilical-catheter and mechanical ventilation was associated with higher risk of HAI in our clinical setting, a surveillance protocol which monitors device-associated infections in all BW classes neonates may represent a useful tool to prevent HAIs in the NICU. The absence of 
national, network-based data in the NICU context impairs benchmarking activities and, thus, may limit surveillance systems' contribution to HAIs prevention.

\begin{abstract}
Abbreviations
HAls: Healthcare-associated infections; NICU: Neonatal intensive care; AS: Active surveillance; UTI: Urinary tract infection; BSI: Bloodstream infection; VAP: Ventilator associated pneumonia; BW: Birth weight; VLBW: Very low birth weight; ELBW: Extremely low BW; CONS: Coagulase negative staphylococci; ESBL: Extended spectrum beta-lactamase; XDR: Extensively drug resistant; CDC: Centers for Disease Control and Prevention; NHSN: National Healthcare Safety Network; NNIS: National Nosocomial Infections Surveillance System; NEO-KISS: Neonatal-Krankenhaus Infektions Surveillance System.
\end{abstract}

\section{Competing interests}

The authors declare that they have no competing interests.

\section{Authors' contributions}

$V C, L B, M B$ and FR collected the clinical and epidemiological data from patient's charts. VDI and MC collected the microbiological data. VC, MT and RZ analyzed and interpreted the data. VC and RZ conceived the study and participated in its design and coordination. VC and LB performed the statistical analysis. VC and RZ wrote the manuscript. All authors read and approved the final manuscript.

\section{Acknowledgements}

The authors wish to thank the staff in the NICU for their help and interest in the study.

\section{Author details \\ 'Department of Public Health, University of Naples "Federico II", Naples, Italy. ${ }^{2}$ AORN dei Colli, Monaldi Hospital, Via L. Bianchi, Naples, Italy. ${ }^{3}$ Department of Molecular Medicine and Medical Biotechnologies, University of Naples "Federico II", Naples, Italy. ${ }^{4}$ Division of Neonatology, Department of Medical Translational Sciences, University of Naples "Federico II", Naples, Italy. ${ }^{5}$ Italian Study Group of Hospital Hygiene, Italian Society of Hygiene, Preventive Medicine and Public Health, (GISIO), Rome, Italy.}

Received: 18 November 2014 Accepted: 13 March 2015 Published online: 25 March 2015

\section{References}

1. Stoll BJ, Hansen NI, Bell EF, Shankaran S, Laptook AR, Walsh MC, et al. Neonatal outcomes of extremely preterm infants from the NICHD neonatal research network. Pediatrics. 2010;123:443-56.

2. Polin RA, Denson S, Brady MT, Committee on Fetus and Newborn; Committee on Infectious Diseases. Epidemiology and diagnosis of health care-associated infections in the NICU. Pediatrics. 2012;129:e1104-9.

3. Edwards JR, Peterson KD, Mu Y, Banerjee S, Allen-Bridson K, Morrell G, et al. National Healthcare Safety Network (NHSN) report: data summary for 2006 through 2008, issued December 2009. Am J Infect Control. 2009;37(10):783-805.

4. Dudeck MA, Horan TC, Peterson KD, Allen-Bridson K, Morrell G, Pollock DA, et al. National Healthcare Safety Network (NHSN) report: data summary for 2009, device-associated module. Am J Infect Control. 2011;39(5):349-67.

5. Vermont Oxford Network (VON) [https://www.vtoxford.org]

6. Horbar JD, Rogowski J, Plsek PE, Delmore P, Edwards WH, Hocker J, et al. Collaborative quality improvement for neonatal intensive care. NIC/Q Project Investigators of the Vermont Oxford Network. Pediatrics. 2001;107:14-22.

7. The Canadian Neonatal Network ${ }^{\text {TM }}$ [http://www.canadianneonatalnetwork.org]

8. Gastmeier P, Geffers C, Schwab F, Mitzner J, Oblader M, Ruden H. Development of a surveillance system for nosocomial infections: the component for neonatal intensive care in Germany. J Hosp Infect. 2004;57:126-31.

9. Geffers C, Baerwolff S, Schwab F, Gastmeier P. Incidence of healthcare-associated infections in high-risk neonates: results from the German surveillance system for very-low-birthweight infants. J Hosp Infect. 2008;68(3):214-21.

10. Vergnano S, Menson E, Kennea N, Embleton N, Russell AB, Watts T, et al. Neonatal infections in England: the NeonIN surveillance network. Arch Dis Child Fetal Neonatal Ed. 2011;96(1):F9-14.
11. CCM, Regione Emilia Romagna, Agenzia sanitaria e sociale regionale dell'Emilia-Romagna, 2013: Sorveglianza nazionale delle infezioni in terapia intensiva (Progetto SITIN) Rapporto (dati 2009-2010). [http://assr.regione. emilia-romagna.it/]

12. Villari $P$, Crispino M, Salvadori A, Scarcella A. Molecular epidemiology of an outbreak of Serratia marcescens in a neonatal intensive care unit. Infect Control Hosp Epidemiol. 2001;22:630-4.

13. Crivaro V, Bagattini M, Salza MF, Raimondi F, Rossano F, Triassi M, et al. Risk factors for extended-spectrum beta-lactamase-producing Serratia marcescens and Klebsiella pneumoniae acquisition in a neonatal intensive care unit J Hosp Infect. 2007;67:135-41.

14. Crivaro V, Di Popolo A, Caprio A, Lambiase A, Di Resta M, Borriello T, et al. Pseudomonas aeruginosa in a neonatal intensive care unit: molecular epidemiology and infection control measures. BMC Infect Dis. 2009;9:70.

15. Giuffrè M, Cipolla D, Bonura C, Geraci DM, Aleo A, Di Noto S, et al. Epidemic spread of ST1-MRSA-IVa in a neonatal intensive care unit, Italy. BMC Pediatr. 2012;12:64.

16. Zarrilli R, Di Popolo A, Bagattini M, Giannouli M, Martino D, Barchitta M, et al. Clonal spread and patients' risk factors for acquisition of extensively drug-resistant Acinetobacter baumannii in a neonatal intensive care unit in Italy. J Hosp Infect. 2012;82:260-5.

17. Romeo O, Delfino D, Cascio A, Lo Passo C, Amorini M, Romeo D, et al. Microsatellite-based genotyping of Candida parapsilosis sensu stricto isolates reveals dominance and persistence of a particular epidemiological clone among neonatal intensive care unit patients. Infect Genet Evol. 2013;13:105-8.

18. Ciofi Degli Atti ML, Cuttini M, Ravà L, Ceradini J, Paolini V, Ciliento G, et al. Trend of healthcare-associated infections in children: annual prevalence surveys in a research hospital in Italy, 2007-2010. J Hosp Infect. 2012;80(1):6-12.

19. Carrieri MP, Stolfi I, Moro ML, Italian Study Group on Hospital Acquired Infections in Neonatal Intensive Care Units. Intercenter variability and time of onset: two crucial issues in the analysis of risk factors for nosocomial sepsis. Pediatr Infect Dis J. 2003;22(7):599-609.

20. Orsi GB, d'Ettorre G, Panero A, Chiarini F, Vullo V, Venditti M. Hospital-acquired infection surveillance in a neonatal intensive care unit. Am J Infect Control. 2009;37:201-3.

21. Auriti C, Ronchetti MP, Pezzotti P, Marrocco G, Quondamcarlo A, Seganti G, et al. Determinants of nosocomial infection in 6 neonatal intensive care units: an Italian multicenter prospective cohort study. Infect Control Hosp Epidemiol. 2010;31(9):926-33.

22. NNIS System. National Nosocomial Infections Surveillance (NNIS) System report, data summary from January 1990-May 1999, issued June 1999. A report from the NNIS System. Am J Infect Control. 1999;27:520-32.

23. Jarvis WR. Benchmarking for prevention: the Centers for Disease Control and Prevention's National Nosocomial Infections Surveillance (NNIS) system experience. Infection. 2003;31:44-8.

24. Horan TC, Andrus M, Dudeck MA. CDC/NHSN surveillance definition of health care-associated infection and criteria for specific types of infections in the acute care setting. Am J Infect Control. 2008;36:309-32. Erratum in: Am J Infect Control. 2008, 36:655.

25. REGIONE CAMPANIA - Giunta Regionale - Seduta del 28 settembre 2007 - Deliberazione N.1715 - Area Generale di Coordinamento N. 20 - Assistenza Sanitaria - Approvazione del Piano Regionale di Prevenzione e Controllo delle infezioni associate all'assistenza sanitaria. BOLLETTINO UFFICIALE DELLA REGIONE CAMPANIA N. 55 DEL 22 OTTOBRE 2007

26. Rosenberger LH, LaPar DJ, Sawyer RG. Infections caused by multidrug resistant organisms are not associated with overall, all-cause mortality in the surgical intensive care unit: the 20,000 foot view. J Am Coll Surg. 2012;214:747-55

27. Goel N, Wattal C, Oberoi JK, Raveendran R, Datta S, Prasad KJ. Trend analysis of antimicrobial consumption and development of resistance in non-fermenters in a tertiary care hospital in Delhi, India. J Antimicrob Chemother. 2011;66:1625-30

28. Haley RW, Culver DH, White JW, Morgan WM, Emori TG, Munn VP, et al. The efficacy of infection surveillance and control programs in preventing nosocomial infections in U.S. hospitals. Am J Epidemiol. 1985;121:182-205.

29. Gastmeier P, Schwab F, Sohr D, Behnke M, Geffers C. Reproducibility of the surveillance effect to decrease nosocomial infection rates. Infect Control Hosp Epidemiol. 2009;30:993-9.

30. Dudeck MA, Horan TC, Peterson KD, Allen-Bridson K, Morrell G, Pollock DA, et al. National Healthcare Safety Network (NHSN) report: data summary for 2010, device-associated module. Am J Infect Control. 2011;39(10):798-816. 
31. KISS Krankenhaus - Infektions - Surveillance - System Modul NEO-KISS Referenzdaten Berechnungszeitraum: Januar 2009 bis Dezember 2013 [http:// www.nrz-hygiene.de/fileadmin/nrz/module/neo/200901_201312_NEORef.pdf]

32. Couto RC, Carvalho EA, Pedrosa TM, Pedroso ER, Neto MC, Biscione FM. A 10-year prospective surveillance of nosocomial infections in neonatal intensive care units. Am J Infect Control. 2007;35:183-9.

33. Verstraete E, Boelens J, De Coen K, Claeys G, Vogelaers D, Vanhaesebrouck $P$, et al. Healthcare-associated bloodstream infections in a neonatal intensive care unit over a 20-year period (1992-2011): trends in incidence, pathogens, and mortality. Infect Control Hosp Epidemiol. 2014;35:511-8.

34. Urzedo JE, Levenhagen MM, Pedroso RS, Abdallah VO, Sabino SS, Brito DV. Nosocomial infections in a neonatal intensive care unit during 16 years: 1997-2012. Rev Soc Bras Med Trop. 2014;47:321-6.

\section{Submit your next manuscript to BioMed Central and take full advantage of:}

- Convenient online submission

- Thorough peer review

- No space constraints or color figure charges

- Immediate publication on acceptance

- Inclusion in PubMed, CAS, Scopus and Google Scholar

- Research which is freely available for redistribution 